\title{
Genome-Wide Analysis of Purple Acid Phosphatase Genes in Brassica rapa and Their Association with Pollen Development and Phosphorus Deprivation Stress
}

\author{
Yongfang Cai, Jiao Qi, Chun Li, Kehui Miao, Baixue Jiang, Xiaoshuang Yang, Wenyu Han, Yang Wang, Jing Gao* \\ and Xiangshu Dong *DiD
}

check for updates

Citation: Cai, Y.; Qi, J.; Li, C.; Miao, K.; Jiang, B.; Yang, X.; Han, W.; Wang, Y.; Gao, J.; Dong, X. Genome-Wide Analysis of Purple Acid Phosphatase Genes in Brassica rapa and Their Association with Pollen Developmen and Phosphorus Deprivation Stress. Horticulturae 2021, 7, 363. https:// doi.org/10.3390/horticulturae7100363

Academic Editors: Xiaowu Wang, Jian Wu and Xu Cai

Received: 31 August 2021 Accepted: 30 September 2021 Published: 5 October 2021

Publisher's Note: MDPI stays neutral with regard to jurisdictional claims in published maps and institutional affiliations.

Copyright: (c) 2021 by the authors. Licensee MDPI, Basel, Switzerland. This article is an open access article distributed under the terms and conditions of the Creative Commons Attribution (CC BY) license (https:/ / creativecommons.org/licenses/by/ $4.0 /)$.
School of Agriculture, Yunnan University, Kunming 650091, China; yongfangcai@mail.ynu.edu.cn (Y.C.); qijiao@mail.yun.edu.cn (J.Q.); lichun1177@mail.ynu.edu.cn (C.L.); 631196202@mail.ynu.edu.cn (K.M.); jiangbaixue@mail.ynu.edu.cn (B.J.); yangxiaoshuang@mail.ynu.edu.cn (X.Y.); hanwenyu@mail.ynu.edu.cn (W.H.); wangyang@ynu.edu.cn (Y.W.)

* Correspondence: jinggao@ynu.edu.cn (J.G.); dongxiangshu@ynu.edu.cn (X.D.); Tel.: +86-871-6503-1539 (X.D.)

\begin{abstract}
PAPs (purple acid phosphatases) belong to the metallo-phosphoesterase superfamily and play important roles in developmental processes, phosphorus foraging, and recycling. However, the specific functions of BrPAPs in Brassica rapa are poorly understood. In this study, $39 \mathrm{BrPAPS}$ were identified and divided into three major clades and nine subgroups. In 8 of the 39 BrPAPs, some invariant amino acid residues were lost or shifted. Based on an expression profiling analysis, BrPAP11, 14, 20, 24, 29, and 34 were specifically expressed in fertile floral buds, indicating their critical roles during pollen development. A total of $21 \mathrm{BrPAPs}$ responded to Pi deprivation in either shoots or roots. Of these, BrPAP4, 5, 19, and 21 were upregulated in roots under Pi depravation conditions, while BrPAP12 was upregulated in the roots in normal conditions. BrPAP28 was upregulated in shoots under Pi depravation conditions, indicating its function shifted compared with its Arabidopsis homolog, AtPAP26. The present work contributes to further investigation of BrPAPs as candidate genes for genetic improvement studies of low phosphorus tolerance as well as for creating male sterile lines based on gene editing methods in Brassica rapa.
\end{abstract}

Keywords: Brassica rapa; purple acid phosphatases; BrPAP; Pi-deprivation; pollen development

\section{Introduction}

Purple acid phosphatases (PAPs) belong to the metallo-phosphoesterase superfamily and are a type of acid phosphatase (APase) comprised of a binuclear metal center binding Fe (III)-M (II) complex (where $\mathrm{M}=\mathrm{Fe}, \mathrm{Zn}$, or $\mathrm{Mn}$ ) at the active site [1,2]. Due to the existence of a tyrosine residue ligated to a ferric iron, this group of acid phosphatases has a purple color [3]. They have been isolated from most eukaryotic organisms and some bacteria [3,4]. APases can hydrolyze a wide range of anhydrides and phosphate esters [5]. Therefore, improvement of APase activity is an important avenue for improving the efficiency of phosphorus utilization of plants in a low Pi (inorganic phosphate) environment. This enables plants to utilize extracellular and intracellular organic phosphorus (Po) [5-7].

With the aid of five conserved motif blocks (ㅈG/GXXX $\underline{\mathbf{D}} / \mathrm{G} \underline{\mathbf{N H}}(\mathrm{D} / \mathrm{E}) / \mathrm{VXX} \underline{\mathbf{H}} / \mathrm{G} \underline{\mathbf{H}} \times \underline{\mathbf{H}}$ where bold and underlined letters indicate metal ligating residues that are required for metal coordination) and the availability of plant genome sequences, many PAPS have been identified and annotated from plant species at the genomic level $[2,8,9]$. For example, there are 29 PAPs in Arabidopsis thaliana, 38 in Glycine max, 33 in Zea mays ssp. mays var. B73, 19 in Camellia sinensis, 25 in Jatropha curcas, 26 in Oryza sativa, and 25 in Cicer arietinum [2,8-15]. Based on protein mass and structure, the PAPs isolated from plants can be divided into two forms: low molecular-mass monomeric PAPs (LMMs, with a mass of approximately $35 \mathrm{kDa}$ ) and high molecular-mass oligomeric PAPs (HMMs, with a mass around 55-60 kDa) [2,8,15]. 
LMM PAPs usually contain only one catalytic domain, and HMM PAPs are homodimeric or heterodimeric proteins, where each subunit has a C-terminal domain with an active site and an N-terminal domain of unknown function [16].

Due to the APase activity of PAPs, phosphorus acquisition and metabolism are the focus of most studies relating to PAP function. In Arabidopsis, AtPAP10 was induced by Pi starvation and was shown to play a role in plant tolerance to Pi limitation [17]. AtPAP15 was related to the mobilization of phosphorus reserves during seed and pollen germination [18]. AtPAP12 and AtPAP26 appear to be the predominant PAP isozymes responsive to Pi starvation and they can utilize Po $[19,20]$. In rice, APase activity and Po degradation are significantly increased by the overexpression of OsPAP10a, OsPAP10c, and OsPAP21b, and the expression levels of these can be induced by Pi starvation [21-24]. In soybean, GmPAP14 was induced in response to Po and utilized external Po to promote plant growth and development [7].

In addition to phosphorus acquisition and metabolism, the biological functions of PAP genes include other biological processes. Heterologous expression of AtPAP2 in potato can lead to a higher photosynthesis rate, faster growth, higher tuber number, and tuber starch content [25]. In tobacco (Nicotiana tabacum), beta-glucan synthesis and cellulose deposition were increased in NtPAP12 overexpressing cells during cell wall biosynthesis [26]. In soybean, GmPAP3 is related to the adaptation of soybean to $\mathrm{NaCl}$ stress through the involvement of ROS (reactive oxygen species) metabolism processes [27]. In Arabidopsis, seven AtPAPs (AtPAP6, 11, 14, 19, 23, 24, and 25) are predominantly expressed in flowers [4], and AtPAP11 and AtPAP5 are involved in the biological process of pollen tube growth [28]. This implies their potential functions during flower, pollen, and pollen tube development processes. Taken together, evidence suggests that PAPs have diverse functions during plant growth and development under normal or environmental stress conditions.

Brassica rapa is an important vegetable crop in China, Korea, and other Asian countries. PAP genes in B. rapa have been isolated due to the importance of PAPs for plant growth and development [9]. The detailed characteristics and features of $B$. rapa purple acid phosphatase genes (BrPAPs) are limited. In this study, BrPAPs were systematically identified and characterized. In silico and semi-RT-PCR analyses indicated that BrPAP11, 14, 20, 24,29 , and 34 might be related to pollen development, and their potential functions were highlighted by co-expression analyses. The responses of BrPAPs to Pi deprivation conditions were also investigated. The results from this study provide a basis for further understanding of the functions of BrPAPs during pollen development and B. rapa responses to Pi deprivation.

\section{Materials and Methods}

\subsection{Plant Growth and Pi Deprivation Treatment}

Brassica rapa L. ssp. pekinensis 'Chiifu' seeds were germinated in Petri dishes at $23 \pm 1{ }^{\circ} \mathrm{C}$ in darkness. The germinated seeds were sown into plastic pots $(7 \mathrm{~cm} \times 7 \mathrm{~cm})$ filled with vermiculite and grown for $20 \mathrm{~d}$ at $23 \pm 2{ }^{\circ} \mathrm{C}$ with a light intensity of $6000-7000$ Lux on a $16: 8 \mathrm{~h}(\mathrm{~L}: \mathrm{D})$ photoperiod. During this growth phase, the plants were watered every two days with Hoagland solution (in mmol/L: $\mathrm{KNO}_{3}$ 6, $\mathrm{Ca}(\mathrm{NO})_{3} \bullet 4 \mathrm{H}_{2} \mathrm{O} 4, \mathrm{KH}_{2} \mathrm{PO}_{4}$, $\mathrm{MgSO}_{4} \bullet 7 \mathrm{H}_{2} \mathrm{O} 1, \mathrm{H}_{3} \mathrm{BO}_{3} 0.046, \mathrm{MnSO}_{4} \bullet \mathrm{H}_{2} \mathrm{O} 0.014, \mathrm{ZnSO}_{4} \bullet 7 \mathrm{H}_{2} \mathrm{O} 1.36 \times 10^{-3}, \mathrm{CuSO}_{4} \bullet 5 \mathrm{H}_{2} \mathrm{O}$ $4.8 \times 10^{-4},\left(\mathrm{NH}_{4}\right)_{6} \mathrm{MoO}_{24} \bullet 4 \mathrm{H}_{2} \mathrm{O} 1.62 \times 10^{-5}, \mathrm{FeSO}_{4} \bullet 7 \mathrm{H}_{2} \mathrm{O} 2 \times 10^{-5}$, and $\mathrm{C}_{10} \mathrm{H}_{14} \mathrm{~N}_{2} \mathrm{Na}_{2} \mathrm{O}_{8}$ $2 \times 10^{-5}$ ) [29]. The $\mathrm{pH}$ of the solution was adjusted to 6.0 using $\mathrm{HCl}$ and $\mathrm{NaOH}$. For Pi deprivation treatment, the $\mathrm{KH}_{2} \mathrm{PO}_{4}$ in the Hoagland solution was replaced with $\mathrm{KCl}$. After $20 \mathrm{~d}$ of cultivation, 15 to 20 plants were selected randomly. Five plants were used for root length, root weight, fresh weight, leaf area, and phosphorus content measurements. The roots and shoots of the remaining plants were separated and sampled. After sampling, the roots and shoots were frozen immediately in liquid nitrogen and stored at $-80^{\circ} \mathrm{C}$ until use. All Pi deprivation treatments were carried out with three independent biological replicates.

For the fertile and sterile plants of B. rapa, seeds were germinated in Petri dishes at $23 \pm 1{ }^{\circ} \mathrm{C}$ in darkness, then the germinated seeds were transferred to a $4{ }^{\circ} \mathrm{C}$ growth 
chamber in darkness for $30 \mathrm{~d}$ to induce vernalization. After vernalization, the seeds were sown into pots $(15 \times 15 \times 18 \mathrm{~cm})$ containing potting soil and grown in a greenhouse at $23 \pm 1{ }^{\circ} \mathrm{C}$ with a light intensity of 6000-7000 Lux and a 16:8 (L:D) photoperiod. The floral buds were then collected from five plants using three biological replicates, as previously described [30]. Root and shoot tissues were collected from three-week-old seedlings without vernalization. Stems and stem leaf tissues were sampled from these plants seven days after bolting. All tissues were stored at $-80^{\circ} \mathrm{C}$ until use.

\subsection{Leaf Area and Phosphorus Content}

For leaf area determination, the outermost leaf of Chiifu seedlings was dissected, and the leaf area was determined with a Yaxin-1241 leaf meter (Beijing Yaxinliyi, China) following manufacturer's instructions. Total phosphorus concentration was determined as described previously [31]. In brief, $0.2 \mathrm{~g}$ of leaves was ground and extracted using a laboratory-scale high-performance microwave digestion system (Milestone Ethos UP, Italy, Sorisole) with $8 \mathrm{~mL} \mathrm{HNO}_{3}-\mathrm{H}_{2} \mathrm{O}_{2}$ (3:1) reagent. Afterward, the mixtures were reacted with molybdenum blue reagent and measured 20 min later at $700 \mathrm{~nm}$ by using a spectrophotometer (UV-1200, Instrument Co., Ltd., Shanghai, China).

\subsection{Identification of BrPAP Genes in Brassica rapa}

To identify the PAP genes from B. rapa, all putative protein sequences of $B$. rapa (version 3.0) were downloaded from BRAD (http://brassicadb.agridata.cn/brad/ accessed on 28 January 2021) [32]. All of the protein sequences of the 29 AtPAPs (A. thaliana purple acid phosphatase) were retrieved from TAIR (https: / / www.arabidopsis.org/index.jsp; Araport11 accessed on 28 January 2021) based on a previous publication [2] and used as queries to search against all putative protein sequences of B. rapa using BLASTP. A total of 43 putative BrPAP proteins were obtained based on two criteria: an E-value below $10^{-5}$ and sequence identity above $20 \%$. Next, the amino acid sequences of the 43 putative BrPAP proteins were analyzed to determine the presence of conserved sequence

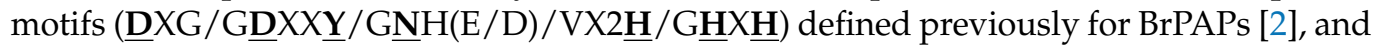
BraA02g012470.3C, BraA04g002700.3C, BraA06g026740.3C, and BraA10g003360.3C were removed. As a result, 39 proteins containing these conserved sequence motifs were identified. To find all potential PAPs in B. rapa, each of the 39 BrPAPs were used as queries for BLAST searching at NCBI and Phytozome 13 (https: / / phytozome-next.jgi.doe.gov / phytomine/ begin.do accessed on 28 January 2021). However, no additional predicted BrPAPs were found. All BrPAPs were named BrPAP1 to BrPAP39 based on their genomic locations.

\subsection{Phylogenetic Tree and Bioinformatics Analysis of BrPAPs}

To carry out phylogenetic tree analysis, the protein sequences of PAPs from Arabidopsis [2] and B. rapa were aligned using MUSCLE with default parameters [33]. An unrooted phylogenetic tree was constructed using MEGA6 with the Neighbor-joining method and parameters set as follows: Jones-Taylor-Thornton (JTT) model, pairwise deletion, and a bootstrap test of 1000 replications [34]. The position of each BrPAP on the B. rapa chromosomes was isolated from BRAD (http:/ / brassicadb.agridata.cn/brad/ accessed on 28 January 2021) and visualized with a custom Python script. The isoelectric point (PI) and molecular weight (M.W.) of BrPAPs were determined using the ProtParam tool (https:// web.expasy.org/protparam/ accessed on 28 January 2021) [35]. Conserved motifs in BrPAPs were identified using the MEME suite 5.1.1 (http:/ / meme-suite.org/ accessed on 28 January 2021) [36]. The predictions of signal peptides and N-glycosylation sites were carried out using SignalP-5.0 (http:/ / www.cbs.dtu.dk/ services/SignalP / accessed on 28 January 2021) [37] and NetNGlyc 1.0 (http:/ / www.cbs.dtu. $\mathrm{dk}$ /services/NetNGlyc/ accessed on 28 January 2021) with default settings, respectively. Gene structures of BrPAPs were drawn using the Gene Structure Display Server (GSDS, version 2.0, http:/ / gsds.cbi.pku.edu.cn/ accessed on 28 January 2021) [38]. 


\subsection{Expression and Co-Expression Analysis of BrPAPs}

All RNA-seq reads from shoots (vernalized and non-vernalized), leaves, stems, roots, flowers, differential developmental seeds, and male sterile lines of B. rapa [39-44] were downloaded from the SRA (sequence read archive) on NCBI (https:/ / www.ncbi.nlm.nih.gov/sra accessed on 28 January 2021) from accession IDs PRJNA339187, PRJNA185152, PRJNA310313, and PRJNA579431. The quality of these RNA-seq reads was analyzed using fastQC (https: / www. bioinformatics.babraham.ac.uk/projects/fastqc/ accessed on 28 January 2021), and the adapter sequences and low-quality reads were removed using the FASTX-Toolkit (Version 0.0.13) [45]. For gene expression, the groomed reads were mapped to genes using Bowtie2 [46], and fragments per kilobases of exons per million mapped reads (FPKM) values for transcripts were calculated using Cufflinks [47]. Heatmaps were generated using Multiple Experiment Viewer (T-MEV) with log transformed FPKM values [48].

For co-expression analysis, RNA-seq data from male sterility lines of $B$. rapa were reassembled $[40,41,43,44]$, and the genes with no differences between fertile and sterile floral buds were removed. Pearson's correlation coefficient (PPC) values were calculated in Excel using BrPAP candidates as queries. The threshold values for PPCs were set between 0.60 and -0.60 . GO (Gene Ontology) enrichment analysis was carried out using agriGO (http:/ /systemsbiology.cau.edu.cn/agriGOv2/ accessed on 28 January 2021) [49] and the clusterProfiler package in R [50].

\subsection{RNA Extraction, Semi-RT-PCR, and qRT-PCR}

Total RNA was isolated using the RNAiso Plus Reagent (Takara Biomedical Technology Co., Ltd., Beijing, China), based on manufacturer protocols. The PrimeScript ${ }^{\mathrm{TM}}$ RT reagent Kit with gDNA Eraser (Takara Biomedical Technology Co., Ltd., Beijing, China) was used to synthesize 1st strand cDNA with $1 \mu \mathrm{g}$ of total RNA. After synthesis, this cDNA was diluted to $10 \mathrm{ng} / \mu \mathrm{L}$ for PCR analysis. Semi-RT-PCR was carried out using $20 \mathrm{ng} / \mu \mathrm{L} \mathrm{cDNA}$ with the following program: denaturation at $94^{\circ} \mathrm{C}$ for $5 \mathrm{~min}$, followed by 28 cycles of $94{ }^{\circ} \mathrm{C}$ for $30 \mathrm{~s}, 55^{\circ} \mathrm{C}$ for $30 \mathrm{~s}$, and $72{ }^{\circ} \mathrm{C}$ for $60 \mathrm{~s}$. For qRT-PCR analysis, $10 \mathrm{ng} / \mu \mathrm{L}$ of cDNA was used and performed with a $30 \mathrm{~s}$ pre-denaturation at $95^{\circ} \mathrm{C}$, followed by 40 cycles of $95^{\circ} \mathrm{C}$ for $5 \mathrm{~s}, 55^{\circ} \mathrm{C}$ for $30 \mathrm{~s}$, and $72{ }^{\circ} \mathrm{C}$ for $60 \mathrm{~s}$. All of the primers used are listed in Table S1. The B. rapa actin gene was used as an internal control. The products of semi-RT-PCR were separated on 1.5\% agarose gels and stained with GeneGreen (Tiangen Technology Co., Ltd., Beijing, China). The qRT-PCR results were analyzed using the $2^{-\Delta \mathrm{Ct}}$ method with three biological replicates. After removing the genes with $\mathrm{Ct}$ value above 35 and less than two-fold change, the results are represented by a heatmap using R scripts with row normalization.

\section{Results}

\subsection{Brassica rapa PAP Genes}

After BLASTP search and conserved motif determination, 39 PAP genes were identified from the B. rapa genome and designated as BrPAP1 to BrPAP39 according to their positions on chromosomes (Figure 1). Among them, 31 BrPAP proteins contained the seven conserved metal-binding residues ( $D, D, Y, N, H, H$, and $H$ ) in five consensus blocks (Table 1). Another three BrPAPs (BrPAP14, BrPAP17, and BrPAP21) lacked the first conserved block. The fourth block was lost in BrPAP9. For BrPAP7, one conserved residue in the fourth block was changed from $\mathrm{H}$ to $\mathrm{S}$ and the fifth block was missing. In the proteins from BrPAP22, BrPAP32, and BrPAP39, one conserved residue in the second block changed from $\mathrm{Y}$ to $\mathrm{F}$, which has been reported in Arabidopsis [2], soybean [51], rice [11], maize [12], chickpea [13], and tea [15]. 


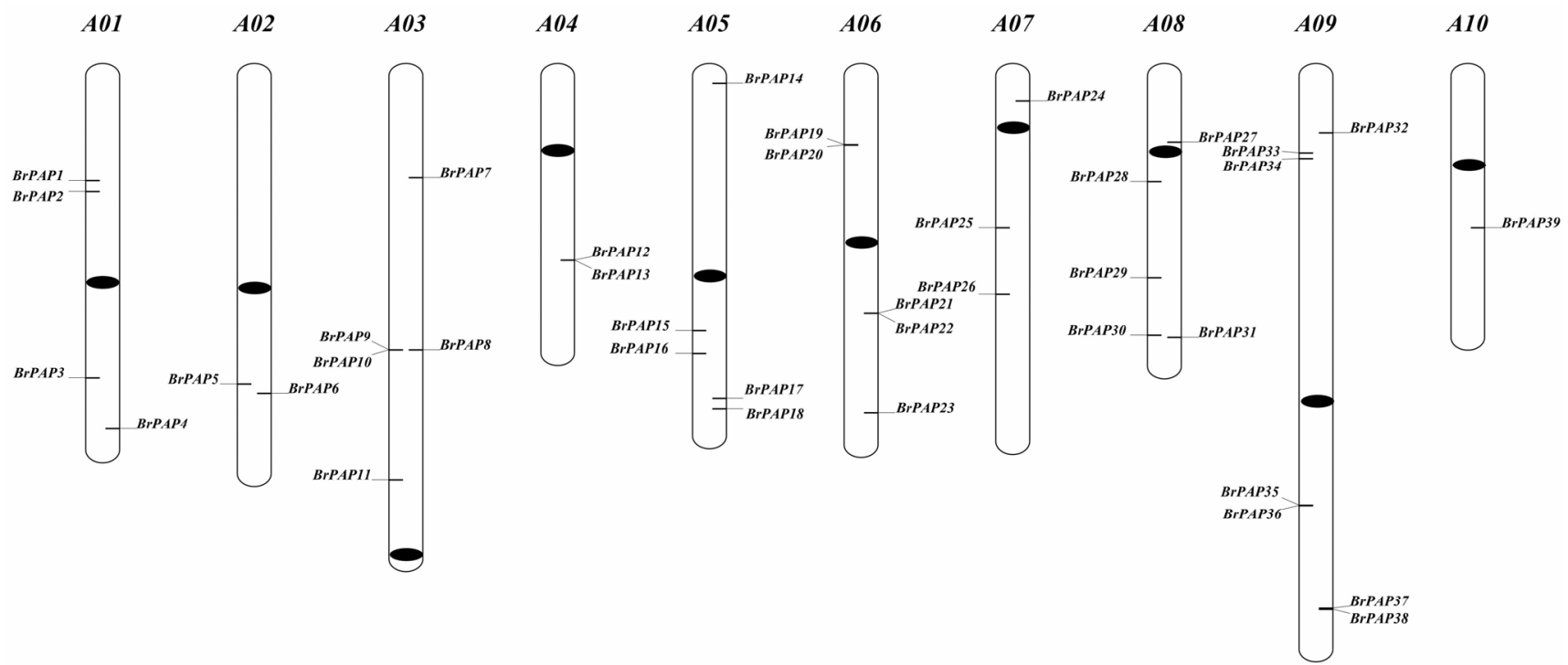

Figure 1. Chromosomal locations of the $39 \mathrm{BrPAP}$ genes identified in this study. Chromosome number is indicated above each chromosome. Black ovals on each chromosome represent centromeric regions.

Table 1. Conserved metal ligating amino acid motifs present in BrPAP proteins. Conserved residues are underlined.

\begin{tabular}{|c|c|c|c|c|c|c|}
\hline \multirow{2}{*}{ Gene ID } & \multirow{2}{*}{$\begin{array}{l}\text { Gene } \\
\text { Name }\end{array}$} & \multicolumn{5}{|c|}{ PAP Conserved Motifs } \\
\hline & & GDXG & GDXXYY & GNH(D/E) & VXX표 & GㅍX표 \\
\hline BraA01g015600.3C & BrPAP1 & GDMG & GDITY & GNHE & FIAH & GHVH \\
\hline BraA01g017190.3C & BrPAP2 & GDLG & GDLSY & GNHE & VLNH & GHVH \\
\hline BraA01g034870.3C & BrPAP3 & GDWG & GDNFY & GNHD & VVGH & GHDH \\
\hline BraA01g041630.3C & BrPAP4 & GDTG & GDVSY & GNHE & VTWH & GHVH \\
\hline BraA02g035210.3C & BrPAP5 & GDWG & GDNFY & GNHD & VVGH & GHDH \\
\hline BraA02g036110.3C & BrPAP6 & GDMG & GDISY & GNHE & VQGH & GHVH \\
\hline BraA03g017330.3C & BrPAP7 & GDLG & CDSCY & GEHE & ATWS & \\
\hline BraA03g043110.3C & BrPAP8 & GDLG & GDFSY & GNHE & VLMH & GHVH \\
\hline BraA03g043120.3C & BrPAP9 & GDLE & YDTKY & GNCD & & \\
\hline BraA03g043130.3C & BrPAP10 & GDLG & GDLSY & GNHE & VLNH & GHVH \\
\hline BraA03g059950.3C & BrPAP11 & GDLG & GDLSY & GNHE & VIVH & GHVH \\
\hline BraA04g019300.3C & BrPAP12 & GDLG & GDLSY & GNHE & VLVH & GHVH \\
\hline BraA04g019310.3C & BrPAP13 & GDLG & GDLSY & GNHE & VLVH & GHVH \\
\hline BraA05g001000.3C & BrPAP14 & & SDMHY & GNHD & VYVH & GHDH \\
\hline BraA05g026730.3C & BrPAP15 & GDLG & GDLSY & GNHE & ALFH & GHVH \\
\hline BraA05g029790.3C & BrPAP16 & GDWG & GDNFY & GNHD & VVGH & GHDH \\
\hline BraA05g036550.3C & BrPAP17 & & GDVVT & GNHD & IFWH & GHNH \\
\hline BraA05g038510.3C & BrPAP18 & GDLG & GDVSY & GNHE & VSWH & GHVH \\
\hline BraA06g009980.3C & BrPAP19 & GDMG & GDICY & GNHE & FLAH & GHAH \\
\hline BraA06g010040.3C & BrPAP20 & GDMG & GDISY & GNHE & VQGH & GHVH \\
\hline BraA06g026750.3C & BrPAP21 & & GDNIF & GNHD & AYFH & GHDH \\
\hline BraA06g026760.3C & BrPAP22 & ADMH & GDNIF & GNHD & AYFH & GHDH \\
\hline BraA06g040030.3C & BrPAP23 & GDWG & GDNFY & GNHD & VVGH & GHDH \\
\hline BraA07g002610.3C & BrPAP24 & GDLG & GDLSY & GNHE & VLVH & GHVH \\
\hline BraA07g012620.3C & BrPAP25 & GDWG & GDNIY & GNHD & VVGH & GHDH \\
\hline BraA07g020920.3C & BrPAP26 & GDLG & GDLSY & GNHE & AVMH & GHIH \\
\hline BraA08g006360.3C & BrPAP27 & GDLG & GDFTY & GNHE & ATMH & GHVH \\
\hline BraA08g009450.3C & BrPAP28 & GDLG & GDLSY & GNHE & VLMH & GHVH \\
\hline BraA08g021060.3C & BrPAP29 & GDLG & GDLAY & GNHE & VMVH & GHVH \\
\hline BraA08g030080.3C & BrPAP30 & GDWG & GDNFY & GNHD & VVGH & GHDH \\
\hline
\end{tabular}


Table 1. Cont.

\begin{tabular}{|c|c|c|c|c|c|c|}
\hline \multirow{2}{*}{ Gene ID } & \multirow{2}{*}{$\begin{array}{l}\text { Gene } \\
\text { Name }\end{array}$} & \multicolumn{5}{|c|}{ PAP Conserved Motifs } \\
\hline & & GDXG & GDXX $\underline{Y}$ & GNH(D/E) & VXX吕 & 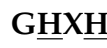 \\
\hline BraA08g030430.3C & BrPAP31 & GDMG & GDISY & GNHE & VQGH & GHVH \\
\hline BraA09g007730.3C & BrPAP32 & ADMH & GDNIF & GNHD & AYFH & $\mathrm{GHDH}$ \\
\hline BraA09g010460.3C & BrPAP33 & GDLG & GDFSY & GNHE & VLMH & GHVH \\
\hline BraA09g011240.3C & BrPAP34 & GDLG & GDLSY & GNHE & VLVH & GHVH \\
\hline BraA09g043870.3C & BrPAP35 & GDLG & GDLSY & GNHE & AVIH & GHVH \\
\hline BraA09g043900.3C & BrPAP36 & GDLG & GDLSY & GNHE & VLLH & GHVH \\
\hline BraA09g059830.3C & BrPAP37 & GDMG & GDISY & GNHE & VQGH & GHVH \\
\hline BraA09g059970.3C & BrPAP38 & GDMG & GDICY & GNHE & FLAH & GHAH \\
\hline BraA10g015040.3C & BrPAР39 & ADMH & GDNIF & GNHD & $\mathrm{AFFH}$ & $\mathrm{GHDH}$ \\
\hline
\end{tabular}

General information for BrPAPs, including gene size, molecular weight, Arabidopsis homologs, and potential N-linked glycosylation sites, were also analyzed (Table 2). The sizes of the genomic DNA sequences for BrPAPs varied from $1196 \mathrm{bp}$ (BrPAP16) to $6766 \mathrm{bp}$ (BrPAP23), with an average length of $2443 \mathrm{bp}$. Molecular weight of identified BrPAPs ranged from $34.8 \mathrm{kDa}$ (BrPAP21) to $75.79 \mathrm{kDa}$ (BrPAP20). Based on predictions from SignalP, signal peptides were found in 34 BrPAPs except for BrPAP2, BrPAP9, BrPAP21, BrPAP25, and BrPAP39. N-glycosylation site prediction analysis indicated that BrPAPs exhibited different numbers of glycosylation sites, from 0 to 6 (Table 2).

\subsection{Phylogenetic and Gene Structure Analyses of BrPAPs}

A phylogenetic analysis was carried out using amino acid sequences from BrPAPs and AtPAPs with the neighbor-joining method. All PAP proteins were classified into three major clades (I to III), and a further classification of these three major clades produced nine subgroups (Figure 2). This analysis was similar to the findings of a previous study in Arabidopsis [2], with one exception. AtPAP10, 12, and 26 were classified into the same group in Arabidopsis [2], whereas AtPAP26 was separated from AtPAP10 and 12 and classified into a new subgroup (I a-3) in this study. Previously, a single gene was identified as a potential ortholog of AtPAP26 in maize and rice, indicating its conserved functions in the Pi deprivation response, which was also observed in B. rapa and was grouped into I a-3 (Figure 2). Based on our phylogenetic analysis, one AtPAP was related to one to three BrPAP homologs, which may have been due to whole-genome polyploidization and a gene loss event of $B$. rapa after separation from Arabidopsis, although this was not the case for AtPAP10 (Table 2 and Figure 2). For AtPAP10, five homologs (BrPAP2, BrPAP8, BrPAP9, BrPAP10, and BrPAP33) were identified in B. rapa, which indicated the expansion of AtPAP10 in B. rapa over evolutionary time.

During the evolution of a multigene family, gene structure usually diversifies. We therefore wanted to study $B r P A P s$ related to their functional diversification and evolution. The intron size and number of BrPAPs were highly variable, showing 11 distinct exonintron organization patterns. Seven exons separated by six introns was the most common organizational pattern and was present in 10 BrPAPs (Table 2 and Figure 3). Except for $B r P A P 6$, most BrPAPs contained more than one intron, indicating the possible existence of alternative splicing during gene expression. For Ia-1, Ilb, and IIIb, genes from the same subgroups showed similar gene structures, indicating that they might have conserved functions. The diversity of gene structures of genes from IIIa implied their diverse functions (Figure 3). 
Table 2. General information for BrPAP genes and their deduced proteins. M.W., molecular weight; PI, isoelectric point.

\begin{tabular}{|c|c|c|c|c|c|c|c|c|c|c|c|}
\hline \multirow{2}{*}{$\begin{array}{l}\text { Gene } \\
\text { Name }\end{array}$} & \multirow{2}{*}{$\begin{array}{c}\text { Chromosome } \\
\text { Location }\end{array}$} & \multirow{2}{*}{$\begin{array}{l}\text { No. of } \\
\text { Exons }\end{array}$} & \multirow{2}{*}{$\begin{array}{c}\text { Gene } \\
\text { Length(bp) }\end{array}$} & \multirow{2}{*}{$\begin{array}{l}\text { M.W. } \\
\text { (kDa) }\end{array}$} & \multirow{2}{*}{$\begin{array}{c}\text { Protein } \\
\text { Length (a.a.) }\end{array}$} & \multirow{2}{*}{$P I$} & \multirow{2}{*}{$\begin{array}{c}\text { Signal Peptide } \\
\text { (Length, Cleave Site) }\end{array}$} & \multirow{2}{*}{$\begin{array}{l}\text { Number of N- } \\
\text { Glycosylation } \\
\text { Sites }\end{array}$} & \multicolumn{3}{|c|}{ Best Hit to Arabidopsis } \\
\hline & & & & & & & & & $A t \_I D$ & At_Name & E-Value \\
\hline BrPAP1 & A01 & 10 & 2778 & 72.67 & 642 & 6.09 & 24, GHA-SN & 1 & AT4G24890.1 & AtPAP24 & 0 \\
\hline BrPAP2 & A01 & 8 & 2942 & 45.42 & 393 & 5.81 & - & 4 & AT2G16430.1 & AtPAP10 & $4.05 \times 10^{-171}$ \\
\hline BrPAP3 & A01 & 3 & 1240 & 37.80 & 334 & 5.28 & 26, TNG-EL & 1 & AT3G17790.1 & AtPAP17 & 0 \\
\hline BrPAP4 & A01 & 6 & 2607 & 60.35 & 541 & 5.23 & 32, SDA-IP & 6 & AT3G07130.1 & AtPAP15 & 0 \\
\hline BrPAP5 & A02 & 7 & 4923 & 37.60 & 331 & 6.3 & 24, SFS-KL & 2 & AT2G01880.1 & AtPAP7 & 0 \\
\hline BrPAP 6 & $\mathrm{~A} 02$ & 1 & 1929 & 72.89 & 643 & 6.07 & 18, VHS-TP & 4 & AT2G03450.1 & AtPAP9 & 0 \\
\hline BrPAP7 & $\mathrm{A} 03$ & 6 & 2705 & 60.27 & 536 & 4.97 & 21, VDA-FP & 6 & AT2G32770.3 & AtPAP13 & 0 \\
\hline BrPAPG & A03 & 4 & 1726 & 34.34 & 309 & 9.37 & - & 1 & AT2G16430.2 & AtPAP10 & $2.48 \times 10^{-51}$ \\
\hline BrPAP10 & A03 & 7 & 2070 & 53.73 & 467 & 7.76 & 25, CNG-GI & 5 & AT2G16430.2 & AtPAP10 & 0 \\
\hline BrPAP11 & A03 & 7 & 1894 & 52.19 & 461 & 6.22 & 22, ING-GM & 3 & AT1G56360.1 & AtPAP 6 & 0 \\
\hline BrPAP12 & A04 & 8 & 2354 & 55.49 & 482 & 6.16 & 28, CDG-GI & 4 & AT2G27190.1 & AtPAP12 & 0 \\
\hline BrPAP13 & A04 & 7 & 2057 & 54.08 & 470 & 6.25 & $28, \mathrm{CDG}-\mathrm{GI}$ & 3 & AT2G27190.1 & AtPAP12 & 0 \\
\hline BrPAP14 & A05 & 5 & 1682 & 44.56 & 394 & 8.47 & $24, \mathrm{VDA}-\mathrm{YG}$ & 1 & AT2G46880.1 & AtPAP14 & 0 \\
\hline BrPAP15 & A05 & 4 & 1947 & 47.48 & 414 & 5.68 & 19, VAA-DD & 0 & AT3G20500.1 & AtPAP18 & 0 \\
\hline BrPAP16 & A05 & 3 & 1196 & 38.33 & 338 & 5.57 & - & 1 & AT3G17790.1 & AtPAP17 & 0 \\
\hline BrPAP17 & A05 & 4 & 1399 & 42.91 & 385 & 5.86 & 23, AVG-WE & 1 & AT3G10150.2 & AtPAP16 & 0 \\
\hline BrPAP18 & A05 & 5 & 2307 & 61.43 & 541 & 5.64 & 26, SSA-DY & 4 & AT3G07130.1 & AtPAP15 & 0 \\
\hline BrPAP21 & A06 & 3 & 1378 & 34.08 & 308 & 6.24 & - & 0 & AT5G63140.1 & AtPAP29 & 0 \\
\hline BrPAP22 & A06 & 3 & 1460 & 42.19 & 383 & 9.01 & 31, ASA-QG & 1 & AT5G63140.1 & AtPAP29 & 0 \\
\hline BrPAP23 & A06 & 14 & 6766 & 69.10 & 607 & 5.51 & 29, SRA-EL & 3 & AT2G01890.1 & AtPAP8 & 0 \\
\hline BrPAP24 & A07 & 7 & 2127 & 52.10 & 460 & 5.86 & 24, SHA-GV & 4 & AT4G36350.1 & AtPAP25 & 0 \\
\hline BrPAP 25 & A07 & 8 & 2551 & 52.34 & 468 & 7.17 & - & 2 & AT1G25230.3 & AtPAP4 & 0 \\
\hline BrPAP26 & A07 & 6 & 4130 & 50.56 & 437 & 8.25 & $22, \mathrm{SQA}-\mathrm{YN}$ & 1 & AT3G52810.1 & AtPAP21 & 0 \\
\hline BrPAP27 & A08 & 7 & 2273 & 61.20 & 548 & 5.02 & 31 , AGG-ES & 4 & AT4G13700.1 & AtPAP23 & 0 \\
\hline BrPAP28 & A08 & 9 & 2313 & 55.40 & 481 & 7.35 & 27, GEG-GI & 1 & AT5G34850.1 & AtPAP 26 & 0 \\
\hline BrPAP29 & A08 & 7 & 1887 & 52.42 & 460 & 6.6 & 19, ING-GI & 1 & AT1G56360.1 & AtPAP6 & 0 \\
\hline BrPAP30 & A08 & 7 & 2595 & 38.03 & 335 & 5.81 & 29, STA-EL & 1 & AT1G14700.1 & AtPAP3 & 0 \\
\hline BrPAP31 & A08 & 2 & 2540 & 73.13 & 652 & 5.95 & 2 , ANA-KA & 6 & AT1G13900.1 & AtPAP2 & 0 \\
\hline BrPAP32 & A09 & 3 & 1746 & 42.92 & 386 & 9.2 & 32, TSS-HR & 2 & AT5G63140.1 & AtPAP29 & 0 \\
\hline BrPAP33 & A09 & 8 & 2490 & 54.12 & 469 & 6.77 & $29, \mathrm{CHG}-\mathrm{GR}$ & 3 & AT2G16430.2 & AtPAP10 & 0 \\
\hline BrPAP34 & A09 & 7 & 1977 & 52.82 & 468 & 5.49 & 23, SHA-GV & 3 & AT2G18130.1 & AtPAP11 & 0 \\
\hline BrPAP35 & A09 & 6 & 2974 & 46.99 & 415 & 6.01 & 21, VSS-YD & 1 & AT3G52780.1 & AtPAP20 & 0 \\
\hline BrPAP36 & A09 & 6 & 3163 & 51.08 & 448 & 5.79 & 35, SQA-DV & 2 & AT3G52820.1 & AtPAP 22 & 0 \\
\hline BrPAP37 & A09 & 2 & 2436 & 73.36 & 653 & 6.18 & 21, ANA-KA & 4 & AT1G13900.1 & AtPAP2 & 0 \\
\hline BrPAP38 & A09 & 9 & 3035 & 69.22 & 622 & 6.16 & 24, ALG-GR & 4 & AT1G13750.1 & AtPAP1 & 0 \\
\hline BrPAP39 & A10 & 4 & 1966 & 45.34 & 404 & 6.83 & - & 3 & AT5G57140.1 & AtPAP28 & 0 \\
\hline
\end{tabular}




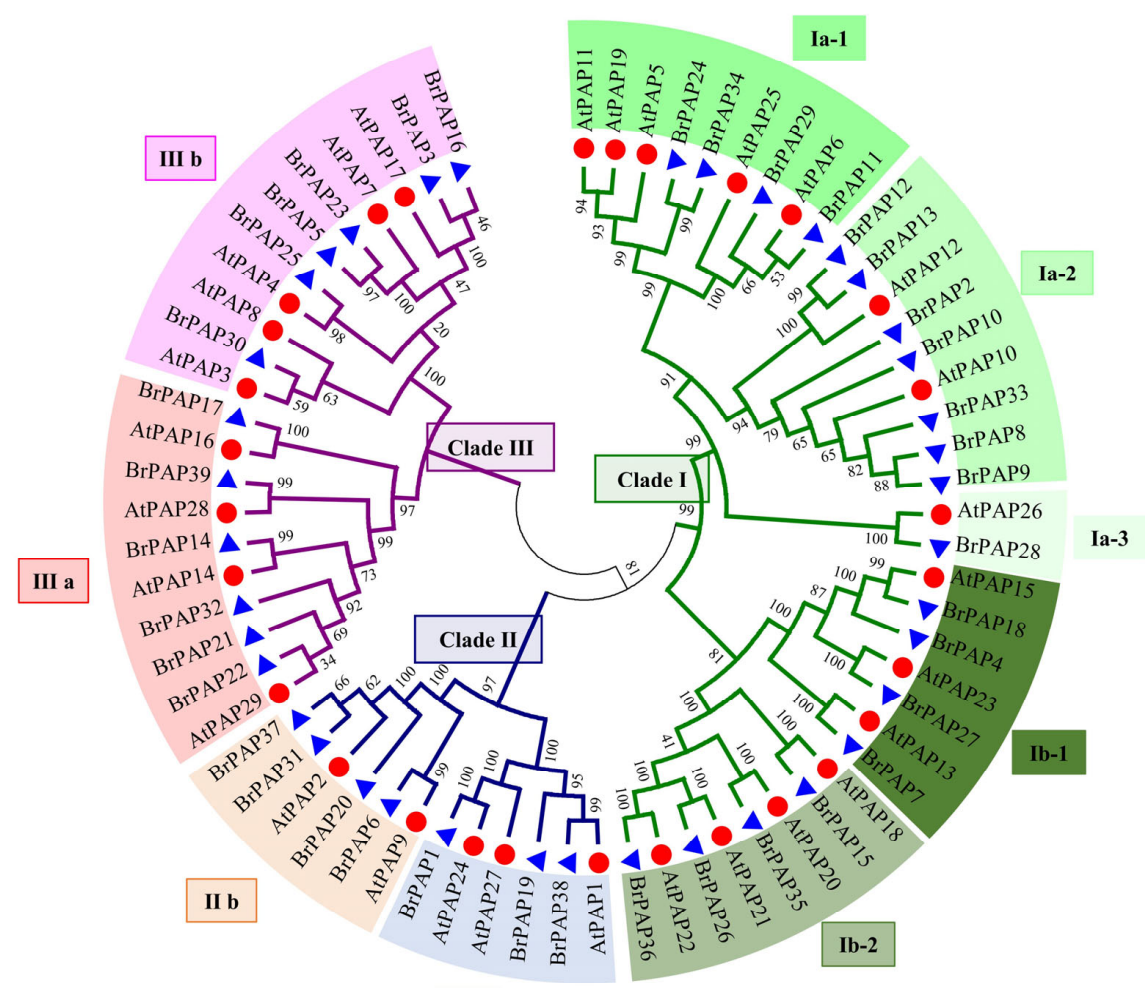

II a

- Brassica rapa

Arabidopsis thaliana

Figure 2. Phylogenetic relationships of BrPAP and AtPAP genes. Multiple protein sequence alignment was performed using ClustalW implemented in MEGA6. A neighbor-joining (NJ) tree was constructed in MEGA6 using the Jones-TaylorThornton (JTT) model with the following options: homogeneous pattern, pairwise deletion, and 1000-replicate bootstrap. Different clades and branches (subclades) are indicated by the colors of the branched lines and background, respectively.

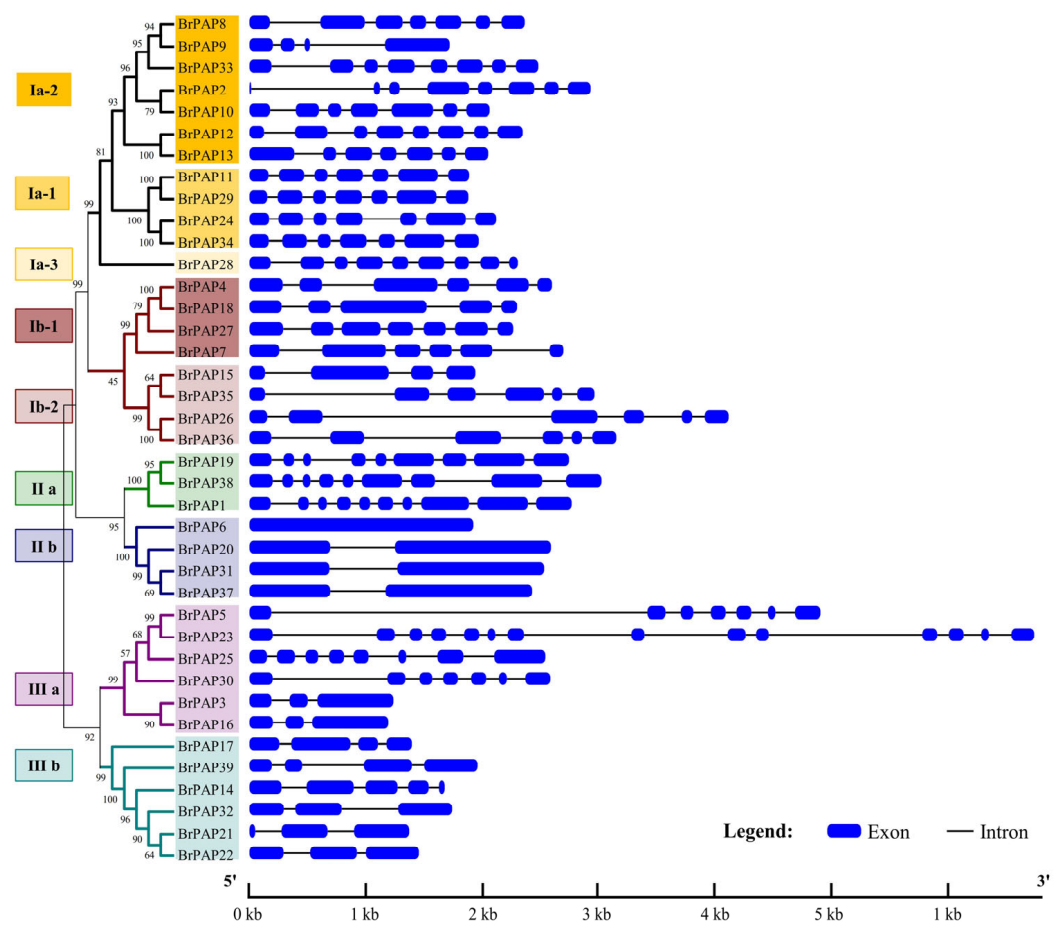

Figure 3. Gene structures of BrPAP genes. 


\subsection{Potential Functions of BrPAPs during Pollen Development}

To study the functional divergence of BrPAPs, the spatial and temporal expression patterns of BrPAPs in B. rapa were analyzed. RNA-seq data derived from shoots (vernalized and non-vernalized), leaves, stems, roots, flowers, differential developmental stages of seeds, and male sterility lines were explored [22,39,41-44]. Based on this RNA-seq data, $B r P A P$ transcripts accumulated in all tissues examined (Figure 4), as previously reported for AtPAPs under standard growth conditions [4]. This indicated that BrPAPs might play diversified functions during development. Interestingly, BrPAP11, 24, 29, and 34 from subgroup Ia-1 showed specific expression in fertile buds in B. rapa (Figure 4). In addition to these four genes, BrPAP14 and 20 also showed high expression in fertile buds in $B$. rapa. This indicated that these genes specifically expressed in fertile buds might be related to pollen development. To confirm the expression patterns of these six genes, different developmental stages of floral buds from genetic male sterility (GMS) lines were collected based on a previous study (Figure 5A) [30]. According to our semi-RT-PCR results, BrPAP11 and 24 were first detected in F2 floral buds (with tetrad pollen), and these $B r P A P s$ were highly expressed in F3 floral buds (with pollen grain after tetrad formation but before maturation) (Figure 5B). BrPAP14 and 29 were highly expressed in both F2 and F3 floral buds. BrPAP20 and BrPAP34 were only expressed in F4 (with pollen grain after tetrad formation but before maturation) and F3 (with mature pollen grains) floral buds, respectively (Figure 5B). To narrow down and predict the functions of BrPAP11, $14,20,24,29$, and 34 during pollen development, we carried out co-expression analysis using previously published male-sterility RNA-seq data in B. rapa $[22,41,43,44]$. When the threshold value for PPC (Pearson's correlation coefficient) was set between 0.60 and $-0.60,1511,979,2355,1593,1886$, and 1667 genes were found to be co-expressed with BrPAP11, 14, 20, 24, 29, and 34, respectively (Table S2 and Figure 6A). GO enrichment analysis was carried out to highlight the biological processes influenced by targeted BrPAPS (Figure 6B). The pollen development process was overrepresented by the co-expressed genes of BrPAP11, 20, 24, and 34. The pollination process was only highlighted by the co-expressed genes of BrPAP20,24, 29, and 34. Lipid metabolic and fatty acid biosynthetic processes were enriched by co-expressed genes of BrPAP14. Carbohydrate transport, pollen sperm cell differentiation, pectin catabolic, polysaccharide catabolic, cell wall organization, pollen germination, and carbohydrate metabolic processes were only overrepresented by the co-expressed genes of BrPAP20.

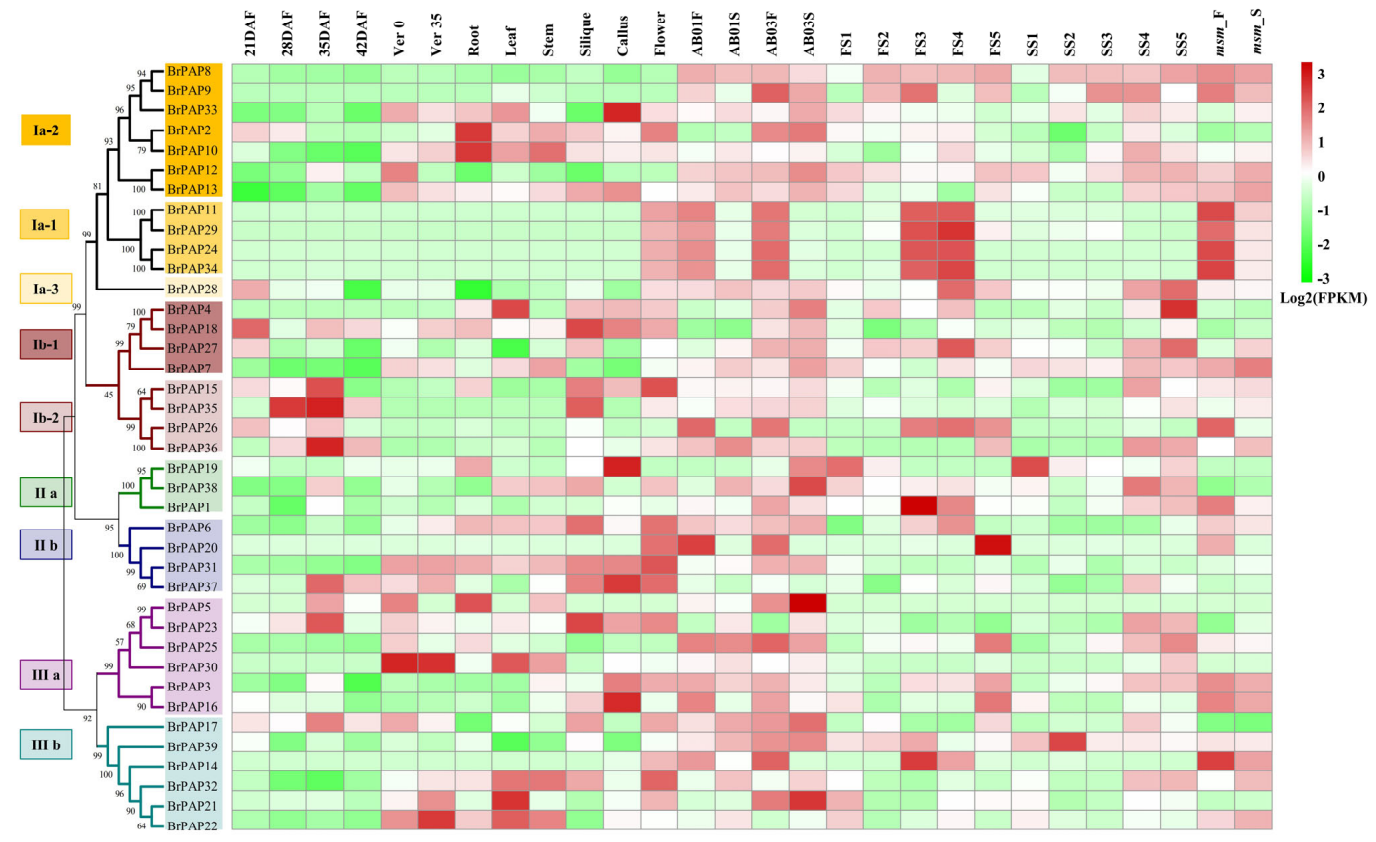

Figure 4. Heatmap representation of expression patterns for BrPAPs with various tissues and male sterility lines. DAF, 
days after flowering; Ver0, 0 day after vernalization; Ver35, 35 days after vernalization; AB01_F and AB01_S, indicate fertile sterile floral buds of GMS Chinese cabbage line 'AB01', respectively; AB03_F and AB03_S represent fertile sterile floral buds of GMS Chinese cabbage line 'AB03', respectively; FS1-FS5, fertile flower buds stage 1 to 5 of GMS Chinese cabbage 'Bcajh97-01A/B'; SS1-SS5, sterile flower buds stage 1 to 5 of GMS Chinese cabbage 'Bcajh97-01A/B; msm_F and msm_S, floral buds from GMS Chinese cabbage line ' $m s m^{\prime}$.

A

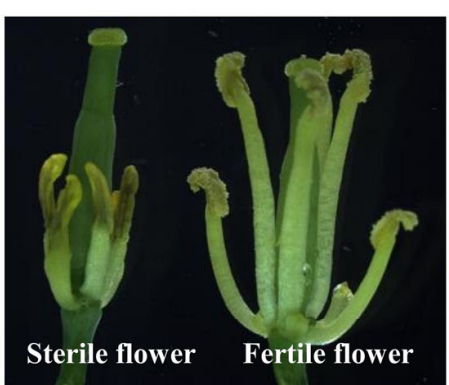

\section{B}

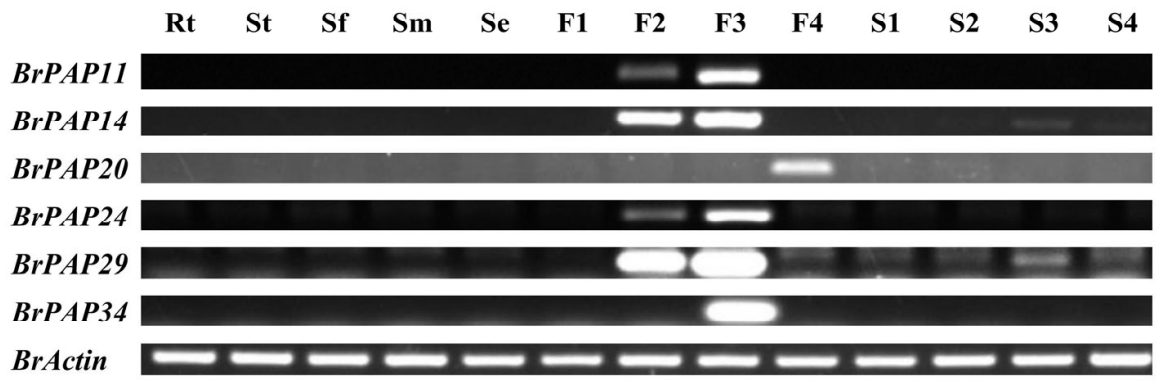

Figure 5. Confirmation of the expression patterns of BrPAPs in fertile buds using semi-RT-PCR. (A) Flower structure of fertile and sterile lines of Brassica rapa. In order to focus on the stamen, the petals and sepals were removed. (B) Analysis of the expression patterns of fertile bud specifically expressed genes using semi-RT-PCR. Rt, root; St, shoot; Sf, stem leaf; Sm, stem; Se, silique; F1-F4 indicated the floral buds from fertile plants. F1, before the tetrad stage. F2, at the tetrad stage. F3, after the tetrad stage but before containing mature pollen. F4, containing mature pollen. S1-S4, floral buds from sterile plants. S1, before the tetrad stage. S2, at the tetrad stage. S3 and S4, after the tetrad stage with aborted pollen grains.

A

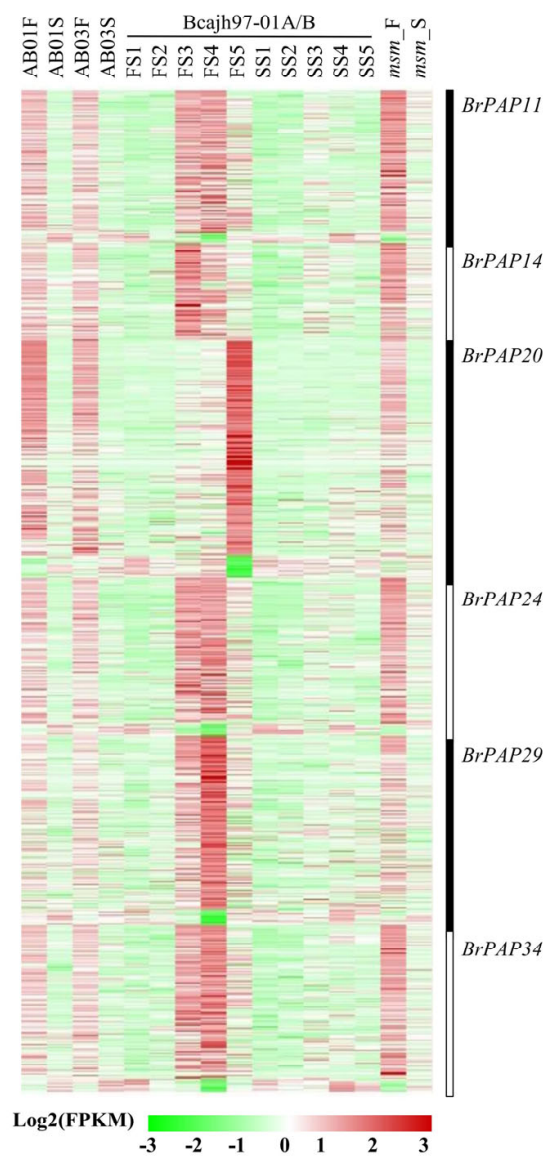

B

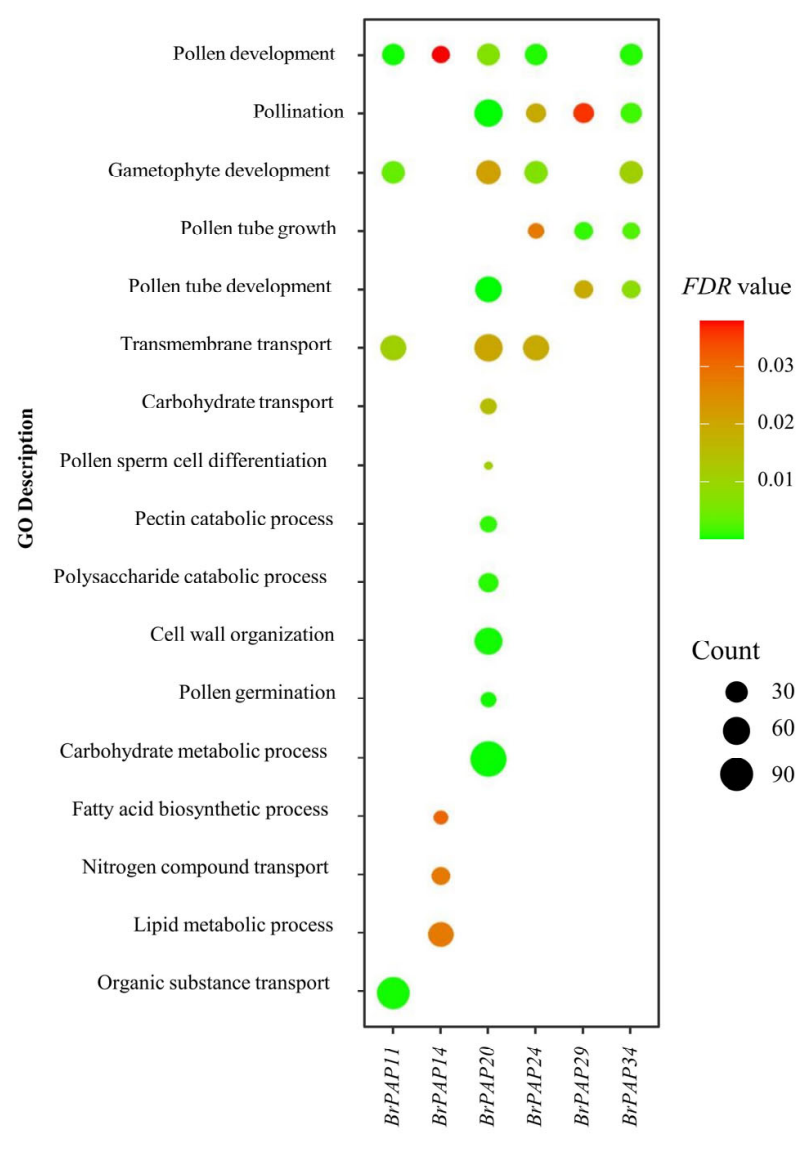

Figure 6. Analysis of co-expression genes of BrPAP11, 14, 20, 24, 29, and 34. (A), Heatmap representation for expression patterns of co-expressed genes of BrPAP11, 14, 20, 24, 29, and 34. (B), GO enrichment analysis of co-expression genes of BrPAP11, 14, 20, 24, 29, and 34 . 


\subsection{Expression of BrPAP Genes in Response to Pi Deprivation in Brassica rapa}

PAPs are considered to play an essential role in the processes of phosphorus foraging and recycling $[5,14]$. To identify the potential functions of BrPAPS related to phosphorus acquisition and utilization, germinated $B$. rapa seeds were sown in pots containing vermiculite and watered with Hoagland solution [28]. For Pi deprivation treatments, the $\mathrm{KH}_{2} \mathrm{PO}_{4}$ in Hoagland solution was replaced with $\mathrm{KCl}$. After treatments, the expression patterns of BrPAPs and physiological characteristics were measured. With Pi deprivation treatment, the plant height, fresh weight, leaf area, and Pi-content were all significantly decreased, while the root-shoot ratio of biomass increased compared with the normal growth condition (Figure 7). The shoot and root parts of seedlings were sampled separately for qRT-PCR analysis. Using a Ct value below 35 and fold change above two as thresholds, $21 \mathrm{BrPAPs}$ responded to Pi deprivation either in shoots or roots (Figure 8 ). Four genes were mainly upregulated in roots under Pi deprivation (Figure 8A). Three genes were upregulated both in shoots and roots under Pi deprivation (Figure $8 \mathrm{~B}$ ). One gene, $\mathrm{BrPAP} 12$, was preferentially upregulated by $\mathrm{Pi}$ deprivation (Figure $8 C$ ). Ten genes were induced by Pi deprivation in shoots (Figure 8D). Three genes were consistently upregulated in shoots (Figure 8E).
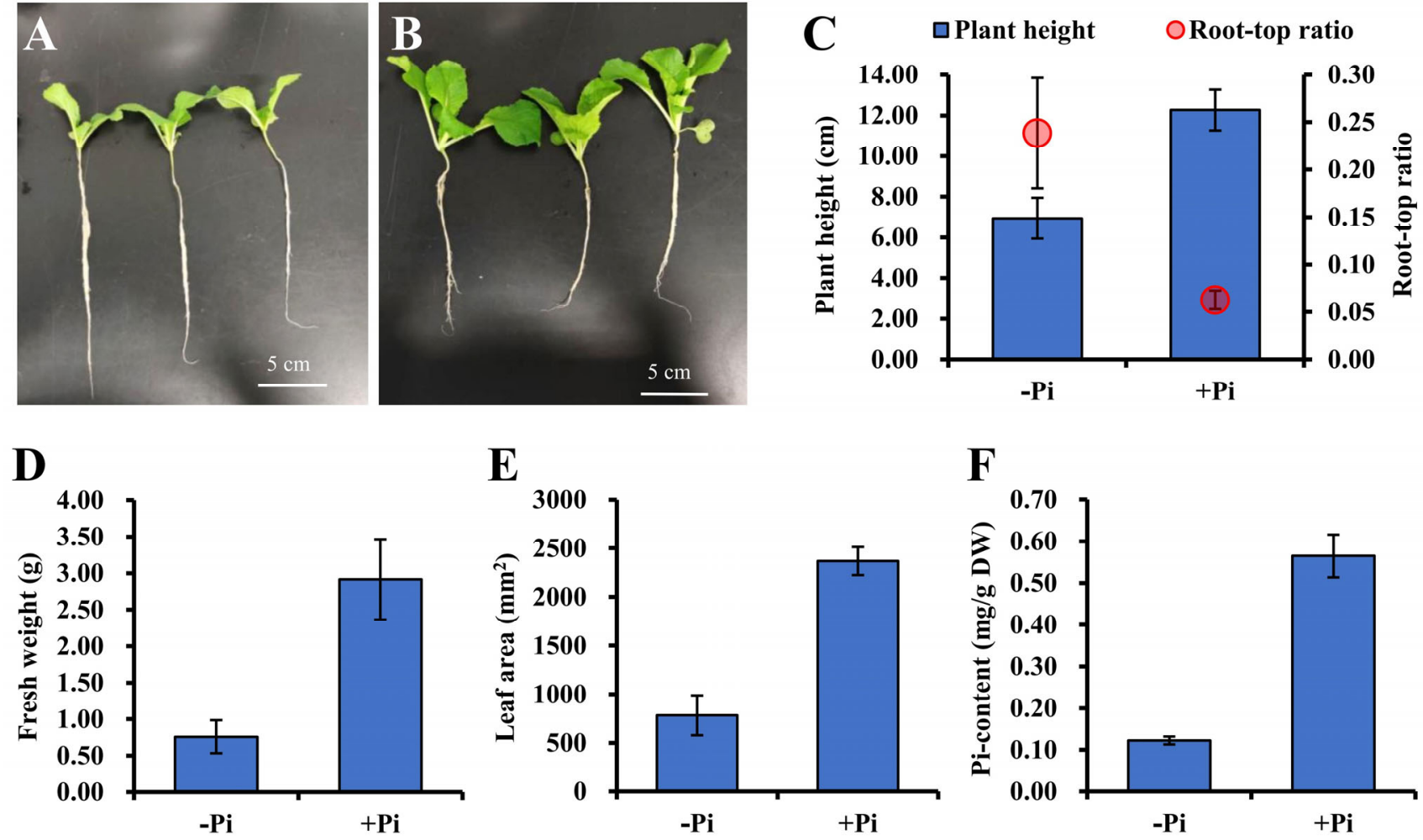

Figure 7. Phenotypical characteristics of Chiifu seedlings after 20 days of Pi deprivation treatment. (A,B) Picture representing Chiifu seedlings under $-\mathrm{Pi}$ or $+\mathrm{Pi}$ growth conditions. (C-F) Plant height, root-shoot ratio of biomass, fresh weight, leaf area, and Pi-content differences of Chiifu seedlings in -Pi or + Pi growth conditions. 


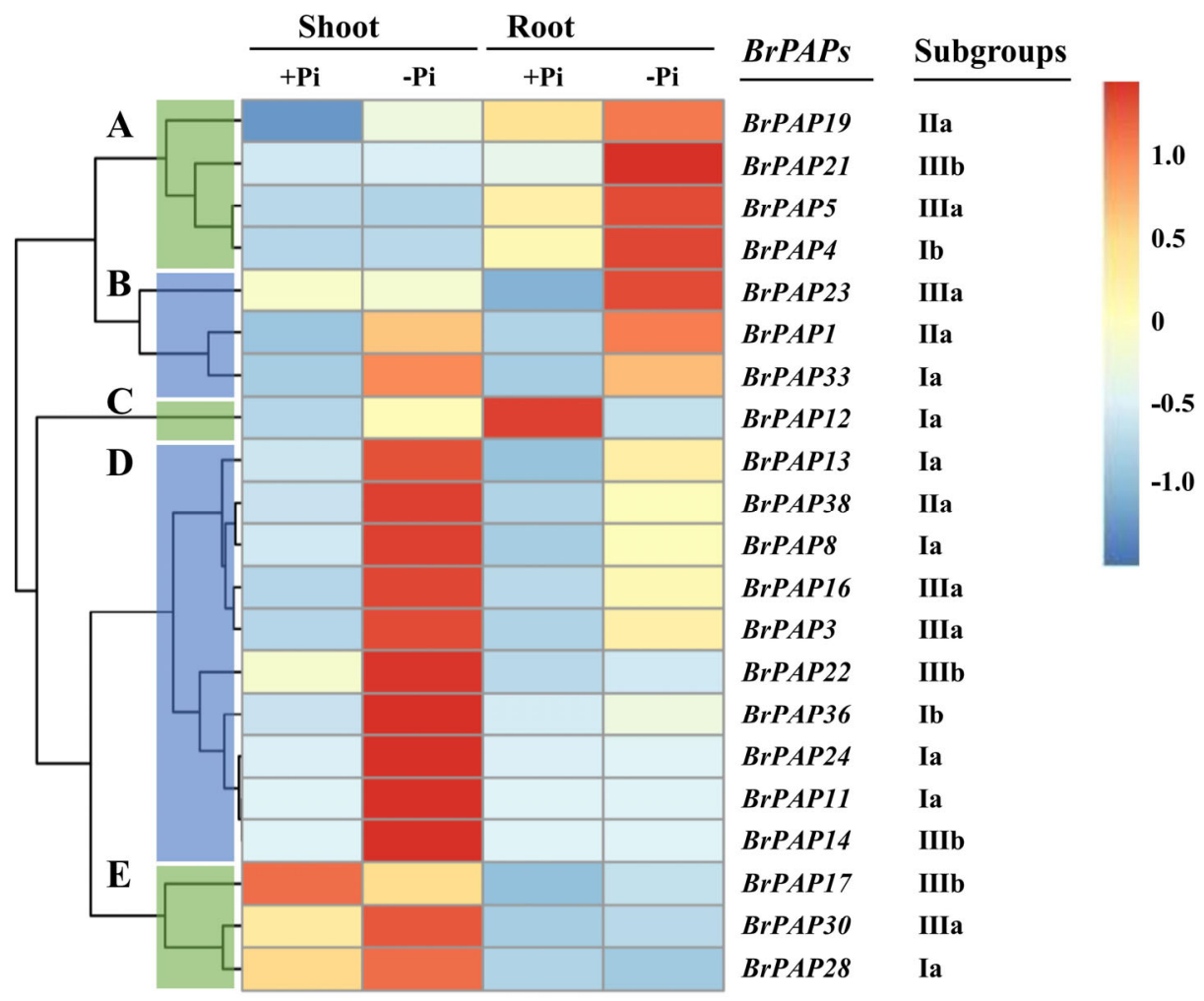

Figure 8. qRT-PCR analysis of expression patterns of BrPAP genes in response to Pi deprivation. (A) Genes upregulated in roots under Pi deprivation. (B) Genes upregulated both in shoots and roots in response to Pi deprivation. (C) Genes upregulated in roots under normal growth conditions. (D) Genes upregulated in shoots under Pi deprivation. (E) Genes upregulated in shoots both under normal and Pi deprivation conditions. The expression of BrPAPs was calculated using the $2^{-\Delta \mathrm{Ct}}$ method and plotted using $\mathrm{R}$ with row normalization.

\section{Discussion}

\subsection{Identification and Analysis of BrPAPs}

Based on conserved sequences and motifs, genome-wide analysis of PAPs has been performed on many plants, including Arabidopsis [2], soybean [51], maize [12], tea [15], rice [11], Brassica napus [10], and ten vegetable species [9]. In this study, $39 \mathrm{BrPAPs}$ were identified and classified into three different clades with nine subgroups based on a phylogenetic analysis using PAPs from Arabidopsis and B. rapa (Figure 2). Previously, 37 BrPAPs were identified in $B$. rapa [9], which could be explained by the fact that a higher genome version was used [32], leading to significantly higher accuracy of identification of BrPAPs [9]. The classification results in our study are mostly consistent with previous results from Arabidopsis and rice [2,11]. AtPAP26 from Ia-2 clustered into Ia-3 with BrPAP28 (Figure 2) [2]. Due to the whole-genome duplication events and gene loss events that have occurred in B. rapa over evolutionary time, one Arabidopsis gene usually has one to three B. rapa homologs [32], and the results from this study also demonstrated this observation except for AtPAP10. Based on our phylogenetic analysis, AtPAP10 corresponded to five BrPAPs (BrPAP2, BrPAP8, BrPAP9, BrPAP10, and BrPAP33), indicating the functional expansion of AtPAP10 (Figure 2). Consistent with studies in maize and rice, only one single gene, BrPAP28, was identified to be the ortholog of AtPAP26 in subgroup Ia-3, indicating its highly conserved function during evolution (Figure 2) [12].

Based on the results from Arabidopsis, rice, maize and other plants, some PAPs lack the invariant amino acid residues involved in the coordination of the di-metal nuclear center of known PAPs [2,11,12]. In B. rapa, 31 of 39 BrPAPs contained seven invariant amino acid residues (Table 1). The first block was absent in BrPAP14, BrPAP17, and BrPAP21. BrPAP9 did not possess the fourth and fifth blocks, and the fifth block was also lost in BrPAP7. 
The third invariant amino acid residue $\mathrm{Y}$ shifted to $\mathrm{T}$ or $\mathrm{F}$ in BrPAP17, BrPAP21, BrPAP22, BrPAP32, and BrPAP39. In BrPAP7, the fourth and fifth conserved residues $\mathrm{N}$ and $\mathrm{H}$ were replaced by E and S, respectively. Compared with Arabidopsis, all BrPAPs had Arabidopsis homologs except for BrPAP9, and there was no conserved block absence in Arabidopsis (Tables 1 and 2) [2]. This indicates that these atypical BrPAPs might not be biochemically active PAPs and their true functions need further study.

\subsection{BrPAPs and Pollen Development}

Previous studies have suggested that PAPs play roles in the processes of carbon metabolism [25], cell wall synthesis [26], ROS metabolism, and response to salt stress [27]. Little is known about their functions related to pollen development, even for AtPAP6, 11, $14,19,23,24$, and 25, which are predominantly expressed in flowers [4]. In this study, BrPAP11, 14, 20, 24, 29, and 34 were specifically expressed in fertile floral buds in B. rapa (Figures 4 and 5). Combining the differences between fertile and sterile floral buds in the current and previous studies (Figure 5A) [30], in addition to our semi-RT-PCR results, we concluded that these BrPAPs might function and play different roles during the process of pollen development (Figure 5B). In support of this hypothesis, BrPAP11 was initially expressed in F2 floral buds and highly expressed in F3 floral buds, and its co-expressed genes were involved in the biological processes of organic substance transport, transmembrane transport, gametophyte development, and pollen development. This suggested that BrPAP11 might be associated with nutrition transport during pollen development (Figure 5B). BrPAP14 was specifically expressed in F2 and F3 floral buds, and the biological processes of lipid metabolic, nitrogen compound transport, fatty acid biosynthetic, and pollen development were enriched in its co-expressed genes (Figures $5 \mathrm{~B}$ and $6 \mathrm{~B}$ ). This implies that BrPAP14 might be involved in secondary metabolism during pollen development. The expression levels of BrPAP20 were high in F4 floral buds (containing mature pollen grains), and carbohydrate metabolic, polysaccharide catabolic, and pectin catabolic were enriched in its co-expressed genes (Figures $5 \mathrm{~B}$ and $6 \mathrm{~B}$ ), suggesting that this gene might have functions during pollen maturation. The normal processing of cell wall degradation and reorganization are required for the development and functions of pollen grains [30,41]. In tobacco, NtPAP12 were found binding to the cell wall and enhanced the activities of cellulose and callose synthases [26]. The highlighted cell wall organization process by BrPAP2O and its co-expressed genes indicate that the functions of BrPAP20 might have similar functions during pollen development to NtPAP12 (Figure 6B). Even BrPAP24 had similar expression patterns to those of BrPAP11, and pollination and pollen tube growth were only enriched by BrPAP24 and its co-expressed genes. The processes of transmembrane transport, gametophyte development, and pollen development were enriched by the co-expressed genes of BrPAP11 and BrPAP24. This observation suggests that the functions of BrAPA11 and BrPAP24 partially overlap. A similar phenomenon was observed for BrPAP14 and BrPAP29. For BrPAP34, the biological processes of pollen development, pollination, pollen tube growth, and pollen tube development were revealed by its co-expressed genes based on GO enrichment analysis, highlighting its possible roles during pollen germination and pollen development. Previously, AtPAP5 and 11 were highly expressed in anthers and involved in pollen tube growth processes [28]. In this study, BrPAP11, BrPAP24, BrPAP34, AtPAP11, and AtPAP5 were classified into subgroup Ia-1, indicating the importance of subgroup Ia-1 during pollen tube growth. Phytic acid is one of the most important components of pollen, AtPAP15 and AtPAP23 were expressed in pollen or floral buds with phytase activity in Arabidopsis [4,18], indicating the specifically expressed BrPAP11, 14, 20, 24, 29, and 34 in fertile floral buds might have similar functions. Collectively, these analyses suggest that BrPAP11, 14, 20,24, 29, and 34 have multiple functions during pollen development with some overlap. These findings will assist future molecular breeding for GMS in B. rapa. 


\subsection{Responses of Brassica rapa and BrPAPs under Pi Deprivation Conditions}

Phosphorus is one of most important essential nutrients for plant growth and is involved in many metabolic processes such as respiration and photosynthesis [12]. However, the content of inorganic phosphorus $(\mathrm{Pi})$ is lower than that required for plant growth in most soils, and most phosphorus is present in the Po (organic phosphorus) form or is fixed by iron, calcium, and other elements. This means that plants cannot directly utilize it [52]. APases can enable plants to use intracellular and extracellular organic phosphorus to survive in low Pi conditions [5]. Among the plant APases, PAPs are one of the most important classes and they can be induced by low Pi conditions [53]. In Arabidopsis, several AtPAPs can be induced by Pi deprivation such as AtPAP10, 11, 12, 17, and $26[2,17,54]$. In rice, the overexpression of OsPAP10a and OsPAP10c can improve the utilization of external organic phosphorus, and both of these can be induced by Pi starvation $[21,22,24]$. In the current study, 21 of the 39 BrPAPs were found to be responsive to Pi deprivation and these can be divided into five groups (Figure 8). The first group showed a high expression in roots under Pi deprivation, including BrPAP4, 5, 19, and 21 (Figure 8A). BrPAP1, 23, and 33 were clustered into a second group and their expression patterns were higher in both shoots and roots under Pi deprivation compared with normal growth conditions (Figure $8 \mathrm{~B}$ ). The third group contained only one gene, BrPAP12, which was upregulated in roots in normal conditions and shoots with Pi deprivation (Figure 8C). Most of the Pi deprivationresponsive genes were clustered into the fourth group, which included ten BrPAPs (BrPAP3, $8,11,13,14,16,22,24,36$, and 38 ); these genes were predominantly upregulated in shoots under Pi deprivation (Figure 8D). BrPAP17, 28 and 30 were classified into a fifth group and were upregulated in shoots in both normal and Pi deprivation conditions (Figure 8D). In previous studies, AtPAP10 was specifically induced by Pi limitation on the root surface and was considered to be one of the major Pi starvation-induced APases in Arabidopsis [17,55]. Among BrPAPs, five homologs of BrPAP10 were found and only two of them, BrPAP8 and $B r P A P 33$, were Pi deprivation-responsive genes (Figures 2 and 8), indicating the functional expansion of the AtPAP10 group during evolution. The expression levels of AtPAP12 increased in low phosphate conditions in Arabidopsis, and its homologs, BrPAP12 and BrPAP13, were also induced in shoots under Pi-deprivation (Figures 2 and 8) [2]. AtPAP26 functions as a dual-targeted PAP and is the predominant intracellular APase as well as a major secreted APase in Pi limited conditions [19]. BrPAP28, the homolog of AtPAP26, was only upregulated in shoots in Pi deprivation, indicating that its function had shifted compared with AtPAP26 (Figures 2 and 8E). Future studies exploring BrPAP responses to Pi deprivation will provide insights into the functions of different BrPAPs and novel gene sources for engineering crops with increased tolerance to Pi deprivation.

\section{Conclusions}

We systematically identified and analyzed the BrPAP genes from the $B$. rapa genome at the genome-wide level. A total of $39 \mathrm{BrPAPs}$ were identified and divided into three major clades with nine subgroups. Expression profiles revealed that all BrPAPs were expressed in all examined tissues, thus indicating their various functions under standard conditions. Interestingly, BrPAP11, 14, 20, 24, 29, and 34 were specifically expressed in fertile floral buds, indicating their critical roles during pollen development. Their potential functions were further highlighted by co-expression analysis. Twenty-one BrPAPs responded to $P i$ deprivation in either shoots or roots. Further studies are required to determine the functions of BrPAPs. The information presented here provides a foundation for future investigations to gain a deeper understanding of the roles of each BrPAP as well as the molecular mechanisms underlying pollen development and low Pi tolerance.

Supplementary Materials: The following are available online at https:/ / www.mdpi.com/article/10 .3390 / horticulturae7100363/s1, Table S1: List of primers used in this study, Table S2: List of genes co-expressed with BrPAP11, 14, 20, 24, 29, and 34, with a Pearson's correlation coefficient (PPC) threshold value set between 0.60 and -0.60 . 
Author Contributions: Conceptualization, Y.C.; data curation, Y.W., J.G. and X.D.; formal analysis, Y.C.; funding acquisition, X.D.; project administration, X.D.; supervision, X.D.; validation, J.Q., C.L., K.M., B.J., X.Y. and W.H.; writing-original draft, Y.C.; writing-review and editing, J.G. and X.D. All authors have read and agreed to the published version of the manuscript.

Funding: This research was funded by the National Science Foundation of China (31601771), the Applied Basic Research Project of Yunnan (202001BB050017 and 202101AT070016), and the Yunnan University Innovation Fund for Graduate Students (2019175 and 2020324).

Acknowledgments: We thank LetPub (www.letpub.com accessed on 2 July 2021) for the linguistic assistance and pre-submission expert review.

Conflicts of Interest: The authors declare no conflict of interest. The funders had no role in the design of the study; in the collection, analyses, or interpretation of data; in the writing of the manuscript; or in the decision to publish the results.

\section{References}

1. Barford, D.; Das, A.K.; Egloff, M.-P. The structure and mechanism of protein phosphatases: Insights into catalysis and regulation. Annu. Rev. Biophys. Biomol. Struct. 1998, 27, 133-164. [CrossRef] [PubMed]

2. Li, D.; Zhu, H.; Liu, K.; Liu, X.; Leggewie, G.; Udvardi, M.; Wang, D. Purple acid phosphatases of Arabidopsis thaliana. Comparative analysis and differential regulation by phosphate deprivation. J. Biol. Chem. 2002, 277, 27772-27781. [CrossRef] [PubMed]

3. Schenk, G.; Korsinczky, M.L.; Hume, D.; Hamilton, S.; DeJersey, J. Purple acid phosphatases from bacteria: Similarities to mammalian and plant enzymes. Gene 2000, 255, 419-424. [CrossRef]

4. Zhu, H.; Qian, W.; Lu, X.; Li, D.; Liu, X.; Liu, K.; Wang, D. Expression patterns of purple acid phosphatase genes in Arabidopsis organs and functional analysis of AtPAP23 predominantly transcribed in flower. Plant Mol. Biol. 2005, 59, 581-594. [CrossRef] [PubMed]

5. Tran, H.T.; Hurley, B.A.; Plaxton, W.C. Feeding hungry plants: The role of purple acid phosphatases in phosphate nutrition. Plant Sci. 2010, 179, 14-27. [CrossRef]

6. Xiao, K.; Katagi, H.; Harrison, M.; Wang, Z.-Y. Improved phosphorus acquisition and biomass production in Arabidopsis by transgenic expression of a purple acid phosphatase gene from M. truncatula. Plant Sci. 2006, 170, 191-202. [CrossRef]

7. Kong, Y.; Li, X.; Wang, B.; Li, W.; Du, H.; Zhang, C. The soybean purple acid phosphatase GmPAP14 predominantly enhances external phytate utilization in plants. Front. Plant Sci. 2018, 9, 292. [CrossRef] [PubMed]

8. Zhu, S.; Chen, M.; Liang, C.; Xue, Y.; Lin, S.; Tian, J. Characterization of purple acid phosphatase family and functional analysis of GmPAP7a/7b involved in extracellular ATP utilization in soybean. Front. Plant Sci. 2020, 11, 661. [CrossRef]

9. Xie, L.; Shang, Q. Genome-wide analysis of purple acid phosphatase structure and expression in ten vegetable species. BMC Genom. 2018, 19, 646. [CrossRef]

10. Lu, K.; Chai, Y.R.; Zhang, K.; Wang, R.; Chen, L.; Lei, B.; Lu, J.; Xu, X.F.; Li, J.N. Cloning and characterization of phosphorus starvation inducible Brassica napus PURPLE ACID PHOSPHATASE 12 gene family, and imprinting of a recently evolved MITE-minisatellite twin structure. Theor. Appl. Genet. 2008, 117, 963-975. [CrossRef]

11. Zhang, Q.; Wang, C.; Tian, J.; Li, K.; Shou, H. Identification of rice purple acid phosphatases related to posphate starvation signalling. Plant Biol. 2010, 13, 7-15. [CrossRef]

12. Gonzalez-Munoz, E.; Avendano-Vazquez, A.O.; Montes, R.A.; De Folter, S.; Andres-Hernandez, L.; Abreu-Goodger, C.; Sawers, R.J. The maize (Zea mays ssp. mays var. B73) genome encodes 33 members of the purple acid phosphatase family. Front. Plant Sci. 2015, 6, 341. [CrossRef]

13. Bhadouria, J.; Singh, A.P.; Mehra, P.; Verma, L.; Srivastawa, R.; Parida, S.K.; Giri, J. Identification of purple acid phosphatases in chickpea and potential roles of CaPAP7 in seed phytate accumulation. Sci. Rep. 2017, 7, 11012. [CrossRef]

14. Venkidasamy, B.; Selvaraj, D.; Ramalingam, S. Genome-wide analysis of purple acid phosphatase (PAP) family proteins in Jatropha curcas L. Int. J. Biol. Macromol. 2019, 123, 648-656. [CrossRef]

15. Yin, C.; Wang, F.; Fan, H.; Fang, Y.; Li, W. Identification of tea plant purple acid phosphatase genes and their expression responses to excess iron. Int. J. Mol. Sci. 2019, 20, 1954. [CrossRef]

16. Schenk, G.; Mitić, N.; Hanson, G.R.; Comba, P. Purple acid phosphatase: A journey into the function and mechanism of a colorful enzyme. Coord. Chem. Rev. 2013, 257, 473-482. [CrossRef]

17. Wang, L.; Li, Z.; Qian, W.; Guo, W.; Gao, X.; Huang, L.; Wang, H.; Zhu, H.; Wu, J.W.; Wang, D.; et al. The Arabidopsis purple acid phosphatase AtPAP10 is predominantly associated with the root surface and plays an important role in plant tolerance to phosphate limitation. Plant Physiol. 2011, 157, 1283-1299. [CrossRef] [PubMed]

18. Kuang, R.; Chan, K.H.; Yeung, E.; Lim, B.L. Molecular and biochemical characterization of AtPAP15, a purple acid phosphatase with phytase activity, in Arabidopsis. Plant Physiol. 2009, 151, 199-209. [CrossRef] [PubMed]

19. Tran, H.T.; Qian, W.; Hurley, B.A.; She, Y.M.; Wang, D.; Plaxton, W.C. Biochemical and molecular characterization of AtPAP12 and AtPAP26: The predominant purple acid phosphatase isozymes secreted by phosphate-starved Arabidopsis thaliana. Plant Cell Environ. 2010, 33, 1789-1803. [CrossRef] [PubMed] 
20. Ghahremani, M.; Park, J.; Anderson, E.M.; Marty-Howard, N.J.; Mullen, R.T.; Plaxton, W.C. Lectin AtGAL1 interacts with high-mannose glycoform of the purple acid phosphatase AtPAP26 secreted by phosphate-starved Arabidopsis. Plant Cell Environ. 2019, 42, 1158-1166. [CrossRef]

21. Tian, J.; Wang, C.; Zhang, Q.; He, X.; Whelan, J.; Shou, H. Overexpression of OsPAP10a, a root-associated acid phosphatase, increased extracellular organic phosphorus utilization in rice. J. Integr. Plant Biol. 2012, 54, 631-639. [CrossRef] [PubMed]

22. Lu, L.; Qiu, W.; Gao, W.; Tyerman, S.D.; Shou, H.; Wang, C. OsPAP10c, a novel secreted acid phosphatase in rice, plays an important role in the utilization of external organic phosphorus. Plant Cell Environ. 2016, 39, 2247-2259. [CrossRef] [PubMed]

23. Mehra, P.; Pandey, B.K.; Giri, J. Improvement in phosphate acquisition and utilization by a secretory purple acid phosphatase (OsPAP21b) in rice. Plant Biotechnol. J. 2017, 15, 1054-1067. [CrossRef] [PubMed]

24. Deng, S.; Lu, L.; Li, J.; Du, Z.; Liu, T.; Li, W.; Xu, F.; Shi, L.; Shou, H.; Wang, C. Purple acid phosphatase 10c encodes a major acid phosphatase that regulates plant growth under phosphate-deficient conditions in rice. J. Exp. Bot. 2020, 71, 4321-4332. [CrossRef] [PubMed]

25. Zhang, Y.; Sun, F.; Fettke, J.; Schottler, M.A.; Ramsden, L.; Fernie, A.R.; Lim, B.L. Heterologous expression of AtPAP2 in transgenic potato influences carbon metabolism and tuber development. FEBS Lett. 2014, 588, 3726-3731. [CrossRef] [PubMed]

26. Kaida, R.; Satoh, Y.; Bulone, V.; Yamada, Y.; Kaku, T.; Hayashi, T.; Kaneko, T.S. Activation of beta-glucan synthases by wall-bound purple acid phosphatase in tobacco cells. Plant Physiol. 2009, 150, 1822-1830. [CrossRef] [PubMed]

27. Liao, H.; Wong, F.-L.; Phang, T.-H.; Cheung, M.-Y.; Li, W.-Y.F.; Shao, G.; Yan, X.; Lam, H.-M. GmPAP3, a novel purple acid phosphatase-like gene in soybean induced by $\mathrm{NaCl}$ stress but not phosphorus deficiency. Gene 2003, 318, 103-111. [CrossRef]

28. Lan, P.; Li, W.; Schmidt, W. Genome-wide co-expression analysis predicts protein kinases as important regulators of phosphate deficiency-induced root hair remodeling in Arabidopsis. BMC Genom. 2013, 14, 210. [CrossRef]

29. Hoagland, D.R.; Arnon, D.I. The water-culture method for growing plants without soil. Circular. Calif. Agric. Exp. Stn. 1950, $347,32$.

30. Dong, X.; Feng, H.; Xu, M.; Lee, J.; Kim, Y.K.; Lim, Y.P.; Piao, Z.; Park, Y.D.; Ma, H.; Hur, Y. Comprehensive analysis of genic male sterility-related genes in Brassica rapa using a newly developed Br300K oligomeric chip. PLoS ONE 2013, 8, e72178. [CrossRef]

31. Miao, X.; Miao, Y.; Gong, H.; Tao, S.; Chen, Y.; Chen, Z.; Liao, W. Digestion methods for determining phosphorus content in plants. Chin. Agric. Sci. Bull. 2019, 35, 132-137.

32. Zhang, L.; Cai, X.; Wu, J.; Liu, M.; Grob, S.; Cheng, F.; Liang, J.; Cai, C.; Liu, Z.; Liu, B.; et al. Improved Brassica rapa reference genome by single-molecule sequencing and chromosome conformation capture technologies. Hortic. Res. 2018, 5, 50. [CrossRef]

33. Edgar, R.C. MUSCLE: Multiple sequence alignment with high accuracy and high throughput. Nucleic Acids Res. 2004, 32, $1792-1797$. [CrossRef]

34. Tamura, K.; Stecher, G.; Peterson, D.; Filipski, A.; Kumar, S. MEGA6: Molecular evolutionary genetics analysis version 6.0. Mol. Biol. Evol. 2013, 30, 2725-2729. [CrossRef] [PubMed]

35. Wilkins, M.R.; Gasteiger, E.; Bairoch, A.; Sanchez, J.C.; Williams, K.L.; Appel, R.D.; Hochstrasser, D.F. Protein identification and analysis tools in the ExPASy server. Methods Mol. Biol. 1999, 112, 531-552. [CrossRef] [PubMed]

36. Bailey, T.L.; Boden, M.; Buske, F.A.; Frith, M.; Grant, C.E.; Clementi, L.; Ren, J.; Li, W.W.; Noble, W.S. MEME SUITE: Tools for motif discovery and searching. Nucleic Acids Res. 2009, 37, w202-w208. [CrossRef] [PubMed]

37. Armenteros, J.J.A.; Tsirigos, K.D.; Sonderby, C.K.; Petersen, T.N.; Winther, O.; Brunak, S.; Von Heijne, G.; Nielsen, H.B. SignalP 5.0 improves signal peptide predictions using deep neural networks. Nat. Biotechnol. 2019, 37, 420-423. [CrossRef] [PubMed]

38. Hu, B.; Jin, J.; Guo, A.Y.; Zhang, H.; Luo, J.; Gao, G. GSDS 2.0: An upgraded gene feature visualization server. Bioinformatics 2015, 31, 1296-1297. [CrossRef] [PubMed]

39. Tong, C.; Wang, X.; Yu, J.; Wu, J.; Li, W.; Huang, J.; Dong, C.; Hua, W.; Liu, S. Comprehensive analysis of RNA-seq data reveals the complexity of the transcriptome in Brassica rapa. BMC Genom. 2013, 14, 689. [CrossRef]

40. Liu, C.; Liu, Z.; Li, C.; Zhang, Y.; Feng, H. Comparative transcriptome analysis of fertile and sterile buds from a genetically male sterile line of Chinese cabbage. Vitr. Cell. Dev. Biol. Plant 2016, 52, 130-139. [CrossRef]

41. Zhou, X.; Liu, Z.; Ji, R.; Feng, H. Comparative transcript profiling of fertile and sterile flower buds from multiple-allele-inherited male sterility in Chinese cabbage (Brassica campestris L. ssp. pekinensis). Mol. Genet. Genom. 2017, 292, 967-990. [CrossRef]

42. Lee, Y.H.; Kim, K.S.; Lee, J.E.; Cha, Y.L.; Moon, Y.H.; Song, Y.S.; Jeong, E.G.; Ahn, S.J.; Park, W. Comprehensive transcriptome profiling in relation to seed storage compounds in tetralocular Brassica rapa. J. Plant Growth Regul. 2018, 37, 867-882. [CrossRef]

43. Shen, X.; Xu, L.; Liu, Y.; Dong, H.; Zhou, D.; Zhang, Y.; Lin, S.; Cao, J.; Huang, L. Comparative transcriptome analysis and ChIP-sequencing reveals stage-specific gene expression and regulation profiles associated with pollen wall formation in Brassica rapa. BMC Genom. 2019, 20, 264. [CrossRef] [PubMed]

44. Huang, S.; Peng, S.; Liu, Z.; Li, C.; Tan, C.; Yao, R.; Li, D.; Li, X.; Hou, L.; Feng, H. Investigation of the genes associated with a male sterility mutant (msm) in Chinese cabbage (Brassica campestris ssp. pekinensis) using RNA-Seq. Mol. Genet. Genom. 2020, 295, 233-249. [CrossRef] [PubMed]

45. Blankenberg, D.; Gordon, A.; Von Kuster, G.; Coraor, N.; Taylor, J.; Nekrutenko, A.; Galaxy, T. Manipulation of FASTQ data with Galaxy. Bioinformatics 2010, 26, 1783-1785. [CrossRef]

46. Langmead, B.; Salzberg, S.L. Fast gapped-read alignment with Bowtie 2. Nat. Methods 2012, 9, 357-359. [CrossRef] [PubMed]

47. Trapnell, C.; Williams, B.A.; Pertea, G.; Mortazavi, A.; Kwan, G.; Van Baren, M.J.; Salzberg, S.L.; Wold, B.J.; Pachter, L. Transcript assembly and quantification by RNA-Seq reveals unannotated transcripts and isoform switching during cell differentiation. Nat. Biotechnol. 2010, 28, 511-515. [CrossRef] [PubMed] 
48. Saeed, A.I.; Bhagabati, N.K.; Braisted, J.C.; Liang, W.; Sharov, V.; Howe, E.A.; Li, J.; Thiagarajan, M.; White, J.A.; Quackenbush, J. TM4 microarray software suite. Methods Enzymol. 2006, 411, 134-193. [CrossRef]

49. Tian, T.; Liu, Y.; Yan, H.; You, Q.; Yi, X.; Du, Z.; Xu, W.; Su, Z. agriGO v2.0: A GO analysis toolkit for the agricultural community, 2017 update. Nucleic Acids Res. 2017, 45, W122-W129. [CrossRef]

50. Yu, G.; Wang, L.G.; Han, Y.; He, Q.Y. clusterProfiler: An R package for comparing biological themes among gene clusters. OMICS 2012, 16, 284-287. [CrossRef]

51. Li, C.; Gui, S.; Yang, T.; Walk, T.; Wang, X.; Liao, H. Identification of soybean purple acid phosphatase genes and their expression responses to phosphorus availability and symbiosis. Ann. Bot. 2011, 109, 275-285. [CrossRef] [PubMed]

52. George, T.; Richardson, A. Potential and limitations to improving crops for enhanced phosphorus utilization. In The Ecophysiology of Plant-Phosphorus Interactions; Springer: Dordrecht, The Netherlands, 2008; pp. 247-270.

53. Sun, F.; Liang, C.; Whelan, J.; Yang, J.; Zhang, P.; Lim, B.L. Global transcriptome analysis of AtPAP2-overexpressing Arabidopsis thaliana with elevated ATP. BMC Genom. 2013, 14, 752. [CrossRef] [PubMed]

54. Hurley, B.A.; Tran, H.T.; Marty, N.J.; Park, J.; Snedden, W.A.; Mullen, R.T.; Plaxton, W.C. The dual-targeted purple acid phosphatase isozyme AtPAP26 is essential for efficient acclimation of Arabidopsis to nutritional phosphate deprivation. Plant Physiol. 2010, 153, 1112-1122. [CrossRef]

55. Zhang, Y.; Wang, X.; Lu, S.; Liu, D. A major root-associated acid phosphatase in Arabidopsis, AtPAP10, is regulated by both local and systemic signals under phosphate starvation. J. Exp. Bot. 2014, 65, 6577-6588. [CrossRef] [PubMed] 